\title{
A SOCIOLOGIA POLÍTICA BRASILEIRA EM ANÁLISE: QUATRO VISÕES SOBRE O FUNCIONAMENTO ADMINISTRATIVODOESTADO NOVO
}

\author{
Adriano Codato
}

\begin{abstract}
RESUMO
Nos estudos de Sociologia Politica brasileira, há quatro maneiras diferentes de considerar os departamentos administrativos dos estados, aparelhos criados pela ditadura de Vargas em 1939 como órgãos complementares ao sistema de interventorias federais. Na base dessas interpretações, há também quatro modos diferentes de considerar o próprio regime do Estado Novo (1937-1945). As concepções sobre os departamentos administrativos divergem tanto em função das convicções do observador diante da forma de funcionamento do sistema político autoritário, quanto do papel (político, econômico ou burocrático) dessas agências que o analista julga mais relevante destacar. Analiso neste ensaio as interpretações disponiveis sobre o assunto e enfatizo o que me parecem ser as principais dificuldades e limitações para explicar a relação entre as antigas elites políticas estaduais e as novas instituições políticas federais na década de 1940 no Brasil.
\end{abstract}

PALAVRAS-CHAVE: Estado Novo; Getúlio Vargas; ditadura; departamentos administrativos dos estados; Sociologia Política brasileira.

\section{INTRODUÇÃO}

Os departamentos administrativos - ou "daspinhos", como se convencionou chamar foram criados pelo Decreto-Lei n. $1202 \mathrm{em} 8$ de abril de 1939 (BRASIL, 1939) e começaram a funcionar já no segundo semestre desse ano. Quatro anos mais tarde eles passaram a chamar-se "Conselhos Administrativos" (cf. o Decreto-Lei n. 5 511, de 21 de maio de 1943 (BRASIL, 1943)). Esses departamentos foram projetados para ser, ao lado das interventorias federais nos estados, um dos dois órgãos da administração pública, consertando o vazio burocrático que havia, ou que se imaginava haver, na área política e burocrática desde a imposição da Constituição de 1937. No caso de Reale estar certo, essa "criação engenhosa de Francisco Campos" é uma das "peças mestras" do regime, sendo assim um "elemento essencial à compreensão do sistema estadonovista" (REALE, 1986, vol. 1, p. 165).

O decreto-lei, que previa sua instituição, estipulava duas coisas: sua composição e suas atribuições. Constituídos por uns poucos membros (de acordo com o texto legal, no mínimo quatro e no máximo dez indivíduos, a depender do estado), eles seriam indicados, assim como o
Interventor, pelo Presidente da República em pessoa e deveriam superintender todo o processo decisório estadual, vigiando de perto as decisões do delegado federal.

Esses departamentos, conforme a letra do decreto, teriam de desempenhar três funções diferentes: uma função política - tal qual uma câmara revisora, tinham de examinar (e poderiam vetar, diga-se) todos os projetos de decretos-leis baixados pelo Interventor e pelos prefeitos municipais; uma função econômica - as propostas de orçamento e a execução orçamentária do estado e de todos os municípios do estado estavam condicionadas à sua análise prévia e aprovação; uma função burocrática - eles poderiam, se fosse o caso, propor medidas de readequação da estrutura administrativa dos órgãos estaduais, racionalizando suas rotinas internas, além de redesenhar o organograma do governo "do ponto de vista da economia e eficiência” (BRASIL, 1939, art. 17, alínea "e").

Além dessa enumeração, baseada exclusivamente no texto da legislação, é preciso compreender que diferença essas atribuições têm entre si, quais seus alcances respectivos e o que caracteriza mais a agência no contexto da política dita- 
torial. Na revisão da literatura a seguir, discuto as três tarefas - a política, a econômica e a burocrática. As análises disponíveis até aqui privilegiaram uma ou outra função que (conforme o analista) definia o papel dos departamentos administrativos e, por meio dele, seu perfil institucional. Trato então neste ensaio das versões disponíveis da Sociologia Política brasileira sobre o assunto (e das versões de alguns ideólogos do autoritarismo nacional), enfatizando o que me parecem ser suas principais dificuldades e limitações para explicar a afinidade entre as antigas elites políticas estaduais e as novas instituições políticas federais sob o Estado Novo. Os objetivos aqui são discutir detidamente os diagnósticos que tomam explícita ou implicitamente os departamentos administrativos dos estados como objeto e fazer um balanço das suas dificuldades e, em menor medida, de seus acertos.

\section{FAMÍLIAS DE ARGUMENTOS}

Há quatro maneiras diferentes de considerar os departamentos administrativos dos estados (DAEs). Na base delas, há também quatro maneiras diferentes de considerar o próprio Estado Novo. As concepções sobre esse aparelho divergem tanto em função das convicções do observador diante do modo de funcionamento do regime "varguista", quanto do papel do Departamento que julga mais relevante destacar, papel quase sempre firmado com base apenas nos 56 artigos do Decreto-Lei n. 1 202. Os departamentos são por isso mais a ilustração de uma tese que se quer demonstrar (mesmo que não elaborada explicitamente, como veremos) do que uma questão por si mesma. $\mathrm{Na}$ verdade, conforme minha hipótese de leitura, parece contar mais a compreensão global que o analista tem do processo político brasileiro depois de 1930, ou a compreensão específica do sistema político estadonovista (i. e., de seus mecanismos de operação e legitimação), do que a percepção de três problemas históricos interligados e que me parecem mais decisivos para entender o sentido da introdução, no organograma do Estado, dos DAEs: $i$ ) a nova conformação do espaço político nacional e a repartição do poder entre as diferentes facções das oligarquias; ii) a organização do trabalho burocrático no interior do sistema estatal e a divisão das prerrogativas decisórias entre seus aparelhos e ramos; iii) as diferentes modalidades de representação de interesses que o Estado Novo impôs, aliadas essas modalidades aos tipos de interesses que se pretendia representar (políti- cos, econômicos etc.) com as inúmeras agências criadas pelo regime ditatorial.

A explanação mais conhecida e repetida pela literatura sobre os DAEs é a administrativa. Esses departamentos não seriam nada mais que uma sucursal do Departamento Administrativo do Serviço Público (DASP) - uma espécie de "daspinhos" estaduais - e teriam o mesmo perfil burocrático dos conselhos da área econômica, exceto a representação corporativa que caracterizava esses últimos. Como a finalidade alegada de qualquer aparelho originado do Estado Novo era "racionalizar a administração pública", segundo a expressão da moda, os "daspinhos" nos estados deveriam ter esse emprego também. Daí seu papel puramente técnico, sua composição profissional, seu perfil superespecializado e sua missão saneadora dos costumes políticos nacionais.

A segunda linha de interpretação, que é o oposto da primeira, é de natureza política. Ela subdividese em duas explicações diferentes. Conforme uma argumentação, os departamentos administrativos, situados no mesmo nível hierárquico da Interventoria Federal, eram órgãos de "fiscalização" e seu propósito seria, justamente, controlar o Interventor. A segunda explicação dessa mesma família sustenta que esses departamentos - principal inovação da "Lei Orgânica dos Estados e Municípios", o nome pomposo do Decreto-Lei n. 1202 - representavam, juntamente com a Interventoria e em "colaboração" com ela, o meio burocrático para concretizar, na ponta do sistema político, nada menos que a vontade pessoal do Chefe do Estado nacional.

A terceira linha de interpretação presume que a agência inventada em 1939 pelo Ministro da Justiça e Negócios Interiores era um instrumento para a integração econômica das unidades regionais. Seu propósito tático era vencer as resistências dos poderes locais, sempre dispostos a lutar pela valorização dos seus "produtos" (fossem eles voltados para o comércio externo, fossem para o comércio interno); seu alvo estratégico era a criação de um mercado nacional sob a tutela de um Estado centralizado, do ponto de vista administrativo, e forte, do ponto de vista político.

A quarta e última perspectiva atribui aos departamentos concebidos pela política autoritária função alguma, a não ser decorativa. Em termos objetivos, o aparelho projetado pelo novo Código dos Interventores seria completamente irrelevante 
para compreender-se o jogo de poder entre as novas elites federais e as antigas elites estaduais. Não tendo modificado a organização política nacional, mas somente algumas das práticas usuais da classe política, o acréscimo de autoritarismo representado pelo Estado Novo estaria resumido a uma questão de quantidade - mais em vez de menos - e não de qualidade (já que, nesse capítulo, seguiu-se a matriz do compromisso coronelista entre as várias frações da classe política) ou mesmo de forma (pois foi mantido o informalismo que caracterizava desde sempre os vínculos entre as facções da elite). Vejamos em detalhe cada uma dessas "famílias de argumentos" (family meaning, no sentido dado por Kaplan $^{1}$ ) e os reparos que se pode fazer a elas.

\section{A FUNÇÃO DECORATIVA}

Começo pela quarta interpretação. Ao menos em termos empíricos, é a menos difícil de refutar-se, embora, pelas questões que mobiliza, seja um tanto difícil de ser explicada. Para Martins, as metas a serem cumpridas pelos departamentos administrativos dos estados ficaram somente na intenção do legislador. Isso porque "a ação desse 'Estado centralizado e forte' no plano nacional [...] iria prescindir no Brasil da edificação dos complicados mecanismos de controle que a extensão territorial do País faria prever. É exato que a presença nos estados dos destacamentos do Exército, sobretudo a partir do controle que ele passou a exercer sobre as forças públicas estaduais, projetou a presença do poder central nas diferentes regiões do País. Mas não menos importantes parecem ter sido os mecanismos de lealdades pessoais que vinculavam os Interventores a Vargas. Tanto é assim que ficou praticamente no papel a instituição dos departamentos administrativos (criados em abril de 1939), que teriam por função aprovar atos do Interventor e fiscalizar a execução dos orçamentos estaduais. Tudo se passou, em síntese, como se a fidelidade política a Vargas em plano nacional tivesse por prêmio a autonomia admi-

\footnotetext{
1 "Wittgenstein fornece-nos a esclarecedora metáfora de uma 'família de significados': semelhança de família não é uma questão de existirem traços definidos comuns a todos os membros da família, mas é questão de presença deste ou daquele traço, suficiente para pôr em evidência a semelhança, em quaisquer dos dois membros das famílias" (KAPLAN, 1969, p. 51). Agradeço aos pareceristas da Revista de Sociologia e Política por terem chamado a aten-
} ção para essa sugestão de A. Kaplan. nistrativa em plano estadual. Não eram muito diferentes as práticas políticas vigentes durante a República Velha" (MARTINS, 1983, p. 1198; sem grifos no original).

A afirmação segundo a qual os departamentos teriam permanecido "praticamente no papel" não é somente muito vaga. Ela não encontra qualquer sustentação documental. Tanto o Departamento de São Paulo quanto os dos demais estados realizaram, no período de sua existência, quase uma sessão por dia útil, tendo emitido milhares de pareceres sobre os atos de prefeitos e interventores. Em São Paulo, descontado o ano de 1945, houve, de 1939 a 1947, 1804 reuniões, entre sessões ordinárias e extraordinárias, e foram votados (agora incluindo o ano de 1945) aproximadamente 18 mil pareceres ${ }^{2}$. No caso do Rio Grande do Sul, foram examinados entre setembro de 1939 e outubro de 1945 mais de 14 mil projetos de decretos-leis e processos administrativos. No Paraná, da instituição do Departamento Administrativo até sua extinção, em julho de 1947, ocorreram quase duas mil sessões ordinárias ${ }^{3}$.

Reconheço que, assim tomados, esses dados só desmentem a assertiva segundo a qual os Departamentos não existiram de fato, mas não dizem nada sobre o conteúdo das decisões examinadas pela agência, nem sobre o tipo de atividade (e seu significado) que eles desempenharam no sistema institucional do Estado ditatorial. Talvez Martins quisesse afirmar que as proposições do Departamento Administrativo eram inócuas ou que, no limite, todas corroboravam os atos do Interventor Federal. Mesmo que fosse verdade, isso não nos dispensa de analisar por que e, principalmente, para quê uma instituição inútil - e que cumpria religiosamente e com uma assiduidade notável todos os rituais inúteis da inútil burocracia - deveria existir. Seja como for, o ponto não é esse (se trabalhou ou não, se importou ou não). $\mathrm{Na}$ verdade, o raciocínio acima apóia-se em uma premissa controversa: "O Estado Novo impôs-se e funcionou sem ter de modificar de maneira substancial a organização política do País”. A reformulação das regras do jogo político foi feita, segundo Luciano Martins, "no nível da prática política, pela supressão de direitos (de expressão

\footnotetext{
2 Para ser exato, 17761 pareceres.

3 Para as informações sobre o Rio Grande do Sul, v. Camargo (1983); para o Paraná, cf. Hertz (2004, p. 30-31).
} 
e de associação políticas)". O novo regime, de fato, só se incumbiu da "aplicação autoritária de controles institucionais já existentes". O coronelismo e sua base econômico-social, o latifúndio, permaneceram para garantir a reprodução do sistema de dominação rural. O corporativismo, que não foi inventado em 1937 pela ditadura, foi mantido para "promover a reestruturação do universo [das] elites e, ao mesmo tempo, manter o sistema de dominação urbano". E o populismo que, "através da manipulação dos símbolos nacionais e, em parte, pela construção da imagem do 'pai dos pobres", ao mesmo tempo em que alimentou o prestígio popular de Vargas, fez dele o representante das massas urbanas (MARTINS, 1976, p. $114,115,117,118-119$, respectivamente; sem grifos no original).

Esse juízo inverte a surrada fórmula segundo a qual é preciso que todas as coisas mudem para que tudo permaneça o mesmo. Curiosamente, é preciso que quase nada mude para que o mesmo - ou seja, o esquema básico de dominação - possa ser aperfeiçoado.

Vejo quatro problemas nessa interpretação. O primeiro é supor que a integração de um universo disperso regionalmente e heterogêneo politicamente (cinco regiões, vinte estados, seis subsistemas econômicos diferentes) pudesse ser feita resolvendo a questão social dos coronéis (ao conservar sua fonte de poder - a grande propriedade para manter, dessa maneira, a estrutura global de dominação) e a questão econômica dos industriais (ao enquadrar as associações patronais e confirmar seu acesso privilegiado ao sistema decisório), sem contudo enfrentar, institucionalmente, o desafio político dos grupos da oligarquia que haviam perdido, ou sido privados da, sua capacidade de auto-representação. O segundo problema, decorrente do primeiro, é atribuir às negociações, às transações interpessoais, enfim, à "conciliação" a capacidade de resolver um assunto latente desde 1931, pelo menos: onde pôr a "oligarquia tradicional”, e a de São Paulo em primeiro lugar, derrotada pela Revolução de Outubro? O terceiro é acreditar que, uma vez decidida a questão da representação dos interesses da elite econômica, via corporativismo, estava decidida também a questão da representação política da elite política, via clientelismo. E o quarto problema é a supervalorização, para compensar a depreciação do valor de face dos departamentos administrativos, do mecanismo das interventorias federais nos estados. Explico melhor minhas divergências em relação a esses três últimos pontos.

Se a deferência em relação ao Chefe e a lealdade pessoal que vinculava os políticos ao Presidente eram tão importantes a ponto de viabilizar a centralização política, os processos de governo e mesmo o funcionamento das instituições do Estado, então não há como discordar da conjectura de Bello sobre a sabedoria política de Getúlio Vargas: "Os recursos do seu oportunismo e da sua astúcia política devem ser muito mais variados e muito mais eficientes do que afirmam os seus adversários e inimigos. Doutro modo, não se lhe explicariam os constantes exitos por quase um quarto de século no trato com políticos de todas as colorações, a não ser que se aceite de plano a total incapacidade destes para se acautelarem e defenderem" (BELLO, 1976, p. 287-288).

Parece pouco, para dizer o mínimo, apoiar a governabilidade do sistema e a legitimidade do regime na figura mítica do Presidente superpoderoso. Igualmente, não se pode entender as várias transformações do aparelho do Estado - a criação dos inúmeros conselhos, comissões e órgãos técnicos, antes e depois de 1937 tão-somente em função do processo de industrialização e modernização econômica, idéia que parece embasar e complementar o argumento de Martins ${ }^{4}$. Essa forma de ver a evolução institucional do Estado nacional despreza o jogo político intra-elites, que não desaparece graças à submissão de boa parte dela à liderança de Vargas (ao contrário, torna-se, por isso mesmo, bem mais complicado), e descarta o novo marco institucional que regulará essas disputas, que não está sequer previsto na Carta Constitucional do Estado Novo.

Toda a argumentação de boa parte da literatura, nesse caso, parece girar em torno de três postulados e uma constatação: a expansão do aparelho central do Estado, resultado de uma série de medidas de concentração de funções administrativas no poder Executivo federal, ao mesmo tempo em que aumentou sua capacidade para a "intervenção", estimulou sua autonomia política; essa autonomia permitiu grande liberdade de ação diante das classes que sustentaram o Estado ditato-

\footnotetext{
${ }^{4}$ Essa visão é mais explícita em Diniz (1991).
} 
rial ou foram por ele beneficiadas; a única forma de monitorar as políticas desse Estado autônomo seriam os dispositivos corporativos, isto é, comissões e conselhos governamentais que admitiam a representação regulada dos "interesses privados" junto aos decisores públicos. A atividade política (i.e., a rivalidade e a capacidade de impor-se e influir sobre os decisores) foi então transferida para "a órbita do aparelho do Estado" (MARTINS, 1976, p. 116).

Entretanto, as formas corporativas de participação das elites econômicas nas decisões econômicas que acompanham as transformações burocráticas da década de 1930, por mais virtudes que possuíssem, não poderiam, por si mesmas, resolver também, ou no lugar de, a questão da representação dos interesses políticos no sistema politico. Ao que tudo indica, Miceli tem toda razão ao enfatizar que "As discussões intermináveis a respeito das conseqüências da política econômica [do] pós-30 para a consolidação do capitalismo industrial no País se eximem de lidar com a questão crucial das relações entre os diversos setores da classe dirigente e, por isso mesmo, não conseguem nem mesmo indagar acerca das exigências administrativas, ideológicas e políticas que culminaram com a montagem de um sistema misto de representação e cooptação desde 1930 até hoje [isto é, na década de 1970]" (MICELI, 1991, p. 595; sem grifos no original $)^{5}$.

Existe um obstáculo político, que é o poder residual das oligarquias estaduais, variável de estado para estado e mais significativo no Rio Grande do Sul, em São Paulo ou em Minas Gerais, por exemplo. É aqui que a conciliação a todo custo encontra seu limite. Ou, melhor, é aqui que a idéia

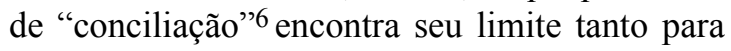
descrever como para explicar a solução para as

\footnotetext{
5 Para a dicotomia representação versus cooptação, v. Schwartzman (1975).

6 A versão clássica dessa perspectiva, formulada por José Honório Rodrigues, não inclui Getúlio Vargas na lista dos conciliadores atávicos. Bem ao contrário, sustenta que seu primeiro governo foi "conciliável e inconciliável". Conciliável com os interesses populares e "inconciliável com os grupos divergentes da própria minoria [política], os que visavam apenas aos compromissos pessoais e partidários". Ao final, "em nome dos princípios do sistema democráticos, a inconciliação [sic] de Getúlio Vargas foi derrotada em 1945" (RODRIGUES, 1965, p. 99).
}

polêmicas questões: como criar a Nação? Como reordenar o universo político brasileiro? Como dirigir o capitalismo brasileiro?

O fato é que o sistema de recompensas mútuas em troca do apoio ao regime tem de ser mais equilibrado para não estimular a pressão dos políticos profissionais para aumentar (ou mesmo para conseguir) sua presença no governo estadual e/ ou federal. O festejado Manifesto dos mineiros de 1943 pode ser lido como um sintoma dessa dificuldade: a defesa altiva das "liberdades públicas e privadas" ou a crítica tímida à "centralização administrativa" e ao "governo monocrático" são a senha para compreender-se a necessidade de um sistema político mais moderno que o coronelismo (sem ser necessariamente menos oligárquico) e menos inflexível que a ditadura pessoal (sem ser necessariamente mais democrático $)^{7}$.

O quarto e último problema dessa visão sobre a irrelevância dos departamentos administrativos (na verdade, sobre a irrelevância de quaisquer dispositivos institucionais da ditadura de Vargas) está ligado não tanto à percepção da inoperância de um lugar destinado exclusivamente aos políticos profissionais no sistema estatal, mas à ignorância da precariedade de existir apenas um lugar desse tipo.

A mediação da relação entre a elite política nacional e as elites políticas estaduais era uma questão tanto burocrática como política. Ou melhor: era uma questão política que demandava, havia muito, uma solução burocrática definitiva. A campanha de 1932, apesar de derrotada, denunciou a urgência do combate às fontes de poder e de autonomia oligárquicos justamente onde não seria possível ou onde não seria seguro simplesmente ativar, como pretende Martins, "os mecanismos de lealdades pessoais que vinculavam os Interventores a Vargas". Nesse sentido, o sistema de interventorias federais poderia ser ora uma solução, ora uma complicação. Ao mesmo tempo em que o Interventor, nomeado pelo Presidente para cuidar da política nos estados, deveria ser burocraticamente forte (até para impor as decisões do governo central) e politicamente independente (em relação às elites regionais - daí, aliás, $\mathrm{o}$ apelo aos "tenentes" logo depois da Revolução,

7 As expressões são literais. Para a íntegra do documento, v. Melo Franco (1979, p. 363-372). 
recurso a essa altura já esgotado), deveria ser também fraco o suficiente para não constituir um novo pólo de poder paralelo ou, no limite, contrário ao Executivo federal. Logo, nem sempre se poderia premiar o preposto presidencial com a dose adequada de "autonomia administrativa em plano estadual". Essa autonomia poderia sempre se converter em rebeldia. A pergunta fundamental aqui parece, portanto, ser: "quem guardaria os guardas?” (CAMPELLO DE SOUZA, 1990 [1976], p. 95). Daí a necessidade política de uma agência administrativa - tal como os departamentos administrativos - para regular (isto é, filtrar e hierarquizar) a expressão dos interesses dos demais grupos políticos estaduais, monitorar o Interventor Federal e garantir à Presidência da República o papel de última instância do sistema decisório.

Essa última observação conduz-nos à segunda visão presente na literatura sobre os departamentos administrativos.

\section{A FUNÇÃO POLÍTICA}

Se a argumentação acima faz algum sentido, isto é, se a exigência de um aparelho superespecializado, destinado a acomodar as elites estaduais resulta de uma série de fatores que o informalismo da relação entre o Presidente e os chefes políticos locais não é capaz de dar conta, então a existência dos departamentos administrativos dos estados poderia ser justificada pelo $p a$ pel político que ele deveria cumprir.

Olhando o organograma do governo depois do Decreto-Lei n. 1 202, o novo arranjo parecia em princípio funcionar como um sistema de "freios e contrapesos" mútuos. Interventor e prefeitos viram-se controlados pelo Departamento, o Departamento pelo Interventor e todos por Vargas por meio de um complicado mecanismo de prestação de contas e de recursos administrativos à Presidência da República via Comissão de Estudos dos Negócios Estaduais e Ministério da Justiça e Negócios Interiores. A questão aqui, todavia, é saber o que contava mais: se a relação política horizontal entre as duas agências e seus ocupantes (Departamento e Interventoria) ou se a relação vertical que subordinava ambas ao Chefe do Estado nacional.

A escolha de uma alternativa ou outra implica enfatizar um objetivo político preciso em detrimento dos demais. Apresento os dois modos de interpretação separadamente e comento-os ao final deste item.

O primeiro modo destaca a relação de controle ("fiscalização") entre o Departamento Administrativo e a Interventoria Federal. Há duas variantes do argumento: esse controle deveria ser (i) políti$c o$ (daí a novidade desse sistema em relação àquele que vigorou na República Velha) ou (ii) meramente burocrático (daí a continuidade política entre o pré-1930 e o pós-1930).

O segundo tipo de interpretação enfatiza a colaboração entre os dois aparelhos e sua submissão estrita à vontade pessoal do Chefe: ambos são apenas uma extensão do poder presidencial e um dos meios disponíveis para efetivar, na ponta do sistema, o programa político "arbitrário" do Executivo federal. Seja como for, na base das duas representações a respeito da configuração institucional do Estado Novo há uma mesma idéia: trata-se de uma adaptação sui generis - improvisada ou planejada, piorada ou melhorada, a depender do analista - das formas de governo do liberalismo clássico (e do princípio da distribuição e equilíbrio entre os "poderes") pelo autoritarismo nacional.

Conforme a visão nativa - produzida, sistematizada e difundida pela coleção de ideólogos autoritários das décadas de 1920 a 1940 -; o regime do Estado Novo incumbiu-se de promover a racionalidade técnica no lugar da odiosa "política tradicional". No entanto, com o Decreto de Abril de 1939 a política tradicional reingressou na estrutura do regime de duas maneiras, pelo menos: em função do lugar que o Departamento Administrativo passou a ocupar no sistema estatal (uma espécie de "legislativo" estadual, segundo se acredita) e do papel que ele desempenhou, ou que ao menos esperava-se que desempenhasse, no jogo intra-elites. Conforme Fausto, "A inclinação centralizadora, revelada desde os primeiros meses após a Revolução de 1930, realizou-se plenamente [em novembro de 1937]. Os estados passaram a ser governados por Interventores, eles próprios controlados, a partir de um decreto-lei de abril de 1939, por um departamento administrativo. Esse departamento era uma espécie de substituto das Assembléias estaduais, pois o orçamento e todos os decretos-leis dos Interventores dependiam de sua aprovação para serem expedidos" (FAUSTO, 1995, p. 366; sem grifos no original). 
Atuando no lugar das câmaras de representantes e tendo por incumbência supervisionar todo o processo decisório estadual, das prefeituras ao governo, dos decretos mais banais ao orçamento anual, é razoável supor que houvesse na prática uma concorrência política entre as duas agências (luta que se expressava burocraticamente, acrescento, por meio dos pareceres do Departamento sobre os decretos do Interventor). Se pudéssemos pôr o problema conforme apresentado por Fausto nos termos do liberalismo clássico, a Interventoria faria o papel de "poder Executivo" e o Departamento Administrativo, o papel de "poder Legislativo". Essa versão extravagante da doutrina da separação dos poderes, note-se, era encorajada pelo próprio Getúlio Vargas. Na visita que fez a Porto Alegre em novembro de 1940, ele discursou para os membros do Departamento Administrativo do Rio Grande do Sul e sentenciou desdenhoso da ordem "liberal-oligárquica" e orgulhoso da obra política do próprio regime: "O Departamento Administrativo substitui, na organização vigente, a antiga Assembléia Legislativa, órgão inoperante, imbuído de espírito individualista, que mascarava a sua atuação estéril com a sonoridade verbal das discussões e quisílias [sic] partidárias" (VARGAS, 1941, p. 219) ${ }^{8}$. Poderia ter acrescentado: faz isso com o concurso de meia dúzia de pessoas no lugar das centenas de deputados estaduais e de vereadores municipais.

A segunda variante da explicação sobre o emprego político dos departamentos administrativos dos estados é mais complexa.

Carone argumentou que essa divisão de trabalho Executivo-Legislativo, embora parecesse muito natural e apropriada ao momento, estava na verdade a serviço de uma medida astuta. Os departa-

8 A auto-imagem que um membro do Departamento paulista fazia da agência era bem mais generosa. Os departamentos administrativos não faziam as vezes das Assembléias Legislativas. Faziam as vezes de qualquer coisa: "O Departamento Administrativo substitui a ação legislativa das Assembléias do Estado, do antigo Senado e da Câmara dos Deputados; substitui as Câmaras Municipais de todo o estado [São Paulo possuía à época 271 municípios]; substitui o Tribunal de Contas na missão que hoje lhe cabe de superintender a aplicação das verbas orçamentárias e a fiel execução da lei de meios. Realiza também o Departamento Administrativo a missão de um órgão de consulta, de um verdadeiro Departamento de Estado [...]" (PAES DE BARROS, s/d, p. 1217; sem grifos no original). Nada disso é falso, embora esteja um tanto fora das devidas proporções. mentos administrativos deveriam ser os loci institucionais que, por meio das funções de fiscalização que estavam expressamente incumbidos de exercer, impediriam que as lideranças regionais se destacassem do controle estrito pretendido por Vargas. A atuação política das forças locais - cujas sedes eram, justamente, a Interventoria e as prefeituras - deveria ficar confinada ao âmbito local. Essa seria, aliás, a condição de sobrevivência das práticas "coronelistas" e do prosseguimento das velhas formas de poder oligárquico sob a proteção (e a retórica, acrescento eu) da racionalidade administrativa. Por isso, não seria exatamente correto imaginar que o Estado Novo representasse uma ruptura tão grande assim com o regime de práticas da República Velha: "as exigências federais [...] não modificam o essencial, que é a existência dos poderes das oligarquias - a terra, o controle de cargos administrativos e políticos etc. [...] Pode-se dizer que durante o Estado Novo permanecem e vigoram todas as formas de domínio oligárquico, com exceção dos limites impostos à escolha do chefe do poder Executivo local" (CARONE, 1977, p. 150, 151, respectivamente). Conclusão: sem alienar suas prerrogativas, o Departamento Administrativo era, para Carone, mais um órgão de controle político-administrativo das rotinas burocráticas da Interventoria do que de controle político stricto sensu dos recursos clientelísticos à disposição do Interventor ${ }^{9}$.

Francisco Campos jamais cogitou a possibilidade de haver continuidade, qualquer que fosse ela, da I República, ou da II, para a III República. Em vez disso, sublinhou, com a conhecida euforia, as mudanças efetivas operadas na estrutura política graças ao decreto-lei de 1939 - e as vantagens evidentes da centralização do poder de Estado no Executivo federal.

Conforme o Ministro da Justiça, o arranjo do sistema estatal dispôs os três aparelhos (Interventoria Federal, Departamento Administra-

\footnotetext{
9 A visão de Nunes sobre os departamentos administrativos é inclassificável. Para ele, a agência tanto fiscalizava a ação dos interventores quanto constituía-se em um instrumento da ação centralizadora do governo federal. Atuava ao mesmo tempo como um "corpo legislativo" e como uma espécie de extensão regional do DASP. O Departamento foi ora um agente do processo de "racionalização do Estado brasileiro", ora uma forma de, por meio da política orçamentária, transferir fundos para a política de clientela (cf. NUNES, 1997, p. 54-55).
} 
tivo e Presidência da República) hierarquicamente. Na base, os dois primeiros; no topo, a última. Isso porque o problema a resolver não era como controlar o poder do Interventor, dificuldade solucionável, como sabemos, com uma simples dispensa. O problema a resolver era, de fato, como mandar no país na direção desejada pela nova classe dirigente, propósito disfarçado sob a retórica da "manutenção da unidade nacional". O circunlóquio nunca pretendeu esconder que a solução para o problema da "integração das forças vivas da nacionalidade" (CAMPOS, 1940e, p. 114) só poderia ser a ditadura pessoal. Em termos mais resumidos: "Um chefe, um povo, uma nação" (CAMPOS, 1940c, p. 214). O que faltaria, contudo, era uma estrutura política capaz de tornar esse propósito uma realidade.

Ao explicar didaticamente (e justificar ideologicamente) a Lei Orgânica dos Estados e Municípios, o Ministro advertiu a audiência que o Decreto-Lei n. 1202 apenas regulamentava o artigo 176 da Constituição de 1937, "organizando" de maneira mais eficiente a intervenção política em todas as unidades da federação. Partindo da premissa de que o Presidente da República era "o centro da nova organização estatal", os instrumentos para consolidar a unidade nacional eram os dois aparelhos (Interventoria e Departamento), juntos. Se o golpe de novembro restituiu o sistema de interventorias, aposentado provisoriamente durante a desajeitada fase dita "constitucional" (1934-1937), o decreto de abril instituiu, como continuação daquela medida saneadora, o Departamento Administrativo. Esse peculiar "sistema de governo", em que o Presidente elegia todo mundo, poderia ser compreendido de dois pontos de vista. Do ponto de vista doutrinário, Departamento Administrativo e Interventoria Federal eram, conforme a oração de Francisco Campos, a encarnação institucional do espírito da Carta de 1937: meros instrumentos políticos de que o Estado Novo dispunha para "fazer chegar a vontade pessoal" do Chefe do Estado nacional a "todos os pontos do País". Do ponto de vista organizacional, o Departamento era, segundo seu criador, apenas um instrumento de "colaboração legislativa e de fiscalização orçamentária" da Interventoria Federal. Não se pretendia, conforme esclarece o Ministro, conter ou superintender o Interventor, que continuava sendo o "principal delegado da União para a administração local". De fato, "a bipartição de atribuições" era "uma simples divisão de traba- lho" e não a expressão da existência de dois poderes, uma vez que, como ensinava Campos, nesse regime só há um Poder, que é o do Presidente da República e que reúne as três funções - executiva e legislativa e judiciária. Portanto, com "poderes delimitados", essas repartições exerciam só "funções delegadas" pelo "Poder Central" 10 .

A maior virtude dessas explicações (CAMPOS, 1940a; FAUSTO, 1972; 1995; CARONE, 1977; LEVINE, 1980) é introduzir, na análise, a função política das instituições políticas, ou mais exatamente, dar o peso devido à estrutura políticoinstitucional do regime ditatorial e dar o peso devido a seus efeitos sobre as práticas políticas. $\mathrm{O}$ maior defeito dessas explicações é que elas fazem isso a partir das disposições legais e não da dinâmica política efetiva, dos conflitos que porventura pudesse haver entre o Presidente, o Interventor e os conselheiros do Departamento Administrativo. Elas são, antes de qualquer coisa, interpretações do decreto-lei e de suas finalidades anunciadas (ou, no caso do Ministro, comemorações da própria clarividência política), não descrições do processo político ou do sistema decisório resultante do "Código dos Interventores", o outro nome do Decreto-Lei n. 1202.

A primeira explicação (Fausto, Carone) deduz do lugar formalmente estipulado para a agência no organograma seu papel efetivo na política estadual. Ainda que o Departamento Administrativo tivesse cumprido a ação delegada de superintendente institucional da Interventoria, por meio da recepção incompleta dos papéis e funções de uma assembléia legislativa melhorada e depurada dos vícios da "era liberal", faltaria determinar como isso foi, de fato, feito. Conforme a lógica simplificada que rege essa visão do processo po-

10 Todas as expressões entre aspas são de Francisco Campos (cf. CAMPOS, 1940c, p. 117, 97, 114-115). Compilei-as e ordenei o argumento. Levine tem a mesma opinião de Campos: a aparelhagem institucional nos estados estava a serviço da centralização do poder no nível federal. "[...] o controle do governo dos municípios e dos estados ficou com os interventores e com toda uma teia de órgãos burocráticos, como a Comissão Federal de Negócios Municipais [o Departamento das Municipalidades] e os departamentos de serviço público dos diversos estados [os departamentos administrativos]. Vargas conseguiu, assim, por reorganização administrativa, em 1939, o que em vão tentara impor politicamente de 1930 a 1937" (LEVINE, 1980, p. 262). 
lítico (dividir para governar), é preciso indagar: tratava-se de um controle burocrático em que, nessa relação, o Departamento exercia seu poder de veto diante das iniciativas da Interventoria, desempenhando, dessa maneira, sua função "legislativa" (o que nos conduz ao estudo do seu processo decisório)? Ou o controle era de outro tipo (político, por exemplo), pois o que havia era uma separação, e uma concorrência, entre uma facção da elite, alojada na Interventoria, e outra facção, diferente e inimiga, alojada no Departamento (o que nos conduz ao estudo dos diversos grupos de políticos profissionais)? Em resumo: instituições diferentes ou elites diferentes?

A segunda dificuldade dessa mesma visão (e esse é, a meu ver, o ponto mais contestável) é que ela parece aceitar, sem se questionar, o pressuposto segundo o qual os departamentos administrativos, por terem ocupado o lugar dos legislativos estaduais, tinham as funções de um poder Legislativo típico. Penso que os assimilar aos legislativos é, no caso, aceitar a publicidade oficial do regime (representada, por exemplo, pela declaração do próprio Vargas reproduzida mais acima) e a ideologia antiparlamentar da época. É em outra dimensão que se deve buscar sua importância: em sua composição (CODATO, 2008) ${ }^{11}$. Sua formação, referida de passagem na seção seguinte, sugere ao menos uma coisa: tratava-se de uma agência para a representação e a expressão dos interesses políticos da elite política. Essa função, frise-se, não se realizava sob a forma parlamentar (seja porque os membros dos departamentos administrativos não eram eleitos, seja porque essa estranha "assembléia" não tinha nem sequer o poder de propor leis), mas sob a forma "burocrática". O que, no caso, faz toda a diferença.

Por fim, a logomaquia autoritária de Francisco Campos revela mais um desejo (no caso, o seu

11 Os estudos de elites revelam certos aspectos da estratificação social e da dinâmica política de uma dada comunidade, associando o poder (sua posse, sua prática) às propriedades sócio-profissionais (procedência, formação, ocupação, treinamento, experiência etc.) daqueles que estão autorizados a exercê-lo. É possível postular, ao menos como ponto de partida para sua demonstração, a existência de uma relação de mão dupla entre as características "pessoais" da elite e as características institucionais do sistema político - aí incluídos o Estado e seus aparelhos, o regime e suas regras e a própria fórmula política (a "ideologia dominante"). próprio) do que uma avaliação científica do desempenho efetivo e da eficiência do sistema institucional dos aparelhos do Estado ditatorial. Como ele foi o inventor do negócio, seu arrazoado conta mais como sintoma do que como diagnóstico. Na equação prosaica que o Ministro montou - contra os antigos "imperialismos regionalistas" seria preciso fortalecer a "unidade da pátria"; a solução seria mudar toda a "fisionomia administrativa" do país; a obra havia começado com o regime de intervenção nos estados, abençoado pela Constituição de 1937; agora ela deveria ser coroada pelas disposições burocráticas do Código dos Interventores que criou os departamentos dos estados - carecemos de saber o principal: esse negócio funcionou? De acordo com sua lógica falaciosa, o Departamento Administrativo deveria promover a centralização administrativa. Ora, não é porque o resultado final da III República foi a centralização administrativa que seu agente foi o Departamento.

Feitas as contas, ou os departamentos administrativos não tinham função política alguma, ou sua função política decorria de outras razões que não as apresentadas nesta seção. Para quem discorda em outorgar aos departamentos administrativos dos estados um papel político efetivo, sobram outras alternativas. E a grande tentação dos analistas foi imputar à agência o privilégio de ser um dos muitos conselhos do Estado cuja incumbência era "racionalizar" o processo decisório. Dessa perspectiva, os "daspinhos" seriam menos um complemento do que um aperfeiçoamento do regime de intervenção federal.

Vejamos a seguir a próxima família de argumentos.

\section{AFUNÇÃO BUROCRÁTICA}

A interpretação mais elaborada e que de fato reconhece a singularidade e a autoridade dos departamentos para a política ditatorial é também a mais problemática, justamente por que realça sua natureza apenas "administrativa".

Foi Loewenstein (1944), em seu estudo pioneiro de sobre o Estado Novo, quem primeiro destacou a função técnica dos departamentos administrativos. Após ter louvado suas virtudes inerentes - "the ingenious system successfully acts as check and control of Interventor while for the individual citizen it fulfills a welcome function as the guarantee of the rule of law against arbitrariness 
and infringement of legal rights by the political official of the state"12 (idem, p. 63-64) -, o autor deriva da análise da composição do Departamento Administrativo do Estado de São Paulo (o tema de seu comentário) a eficiência e sensatez dessa invenção: “[...] the Administrative Department is a team of hard-hitting, hard-working, thoroughly efficient professional bureaucrats - mostly young lawyers, but also technicians such as accountants, civil engineers, agricultural experts, statisticians - while in the Interventor's office the efficiency of the staff is vitiated by ineradicable patronage" 13 (idem, p. 64; sem grifos no original).

Tudo passar-se-ia, nessa concepção, da seguinte forma: "The Interventor acts as the political coordinator of the state, under instructions from Vargas himself, while the Administrative Department, run by bureaucrats, is the legislative body of the state"14 (LOEWENSTEIN, 1944, p. 65 ; sem grifos no original). Sola (1990 [1968] $\left.]^{15}\right)$, em sua síntese sobre o Estado Novo, aceitou essa informação e, repetindo a interpretação proposta por Loewenstein, decidiu que os departamentos administrativos representariam, além do meio pelo qual as atividades do Interventor ficariam subordinadas "aos programas e às ordens federais", um capítulo adicional do programa de racionalização da administração pública, já que ele deveria promover a "introdução de novos padrões de eficiência e de um novo agente social, o burocrata de

12 "O engenhoso sistema atua com sucesso como peso e controle sobre o Interventor, enquanto para o cidadão individual ele preenche uma bem-vinda função como garantia do império da lei contra a arbitrariedade e o desrespeito aos direitos legais pelos agentes políticos do Estado" (tradução do revisor).

13 “'.... O Departamento Administrativo é uma equipe de eficientes, esforçados, inteiramente eficientes burocratas profissionais - em sua maior parte jovens advogados, mas também técnicos como contadores, engenheiros civis, especialistas em agricultura, estatísticos - , ao passo que no gabinete do Interventor a eficiência da equipe é viciada pela inerradicável patronagem" (T. R.).

14 "O Interventor age como se fosse o coordenador político do estado, sob as instruções do próprio Vargas, enquanto o Departamento Administrativo, comandado por burocratas, é o corpo legislativo do estado" (T. R.).

15 Julguei necessário dar a essa e às próximas referências as datas originais de publicação dos textos para se ter uma idéia da evolução do argumento. formação técnica. Esse tipo de organização, que também implicava em hierarquia e dependências, era basicamente diferente daquela que se orientava por critérios predominantemente políticos, de patronagem e de formação de clientela, característica da instituição da Interventoria. Não eram alternativas exclusivas, entretanto, mas correspondiam a diferentes técnicas de ação, de intervenção e de controle que o governo Vargas combinaria habilmente no plano da administração federal" (idem, p. 268-269; sem grifos no original).

Esse tipo de entendimento foi reforçado e amplificado pelo estudo de Campello de Souza (1990 [1976]), sobre a formação das instituições políticas brasileiras após 1945, e tornou-se a interpretação mais aceita da estrutura política do Estado Novo e de seu modo de funcionamento. Ela reproduziu, nesse particular, a incompreensão de Graham (1968) diante da repartição do trabalho tanto político como burocrático no primeiro governo Vargas. Graham, inadvertidamente, assimilou os departamentos administrativos a uma mera divisão regional do DASP. Eles tornaram-se, a partir daí, os "daspinhos". Vale citar aqui a passagem inteira: "Os 'daspinhos' - departamentos estaduais - funcionavam ao mesmo tempo como uma espécie de legislativo estadual e como corpo supervisor para o Interventor e o Ministério da Justiça: os Prefeitos municipais tinham que se submeter não só ao Interventor, mas também ao Departamento Estadual de Serviço Público [sic]. 'Embora o Interventor fosse o responsável pelo estudo, aprovação e declaração de todos os decretos e leis estaduais', observa ainda Graham, “[...] esses só eram válidos quando sancionados pelo presidente do 'daspinho'. Se este se opusesse a algum ato ou decreto executado pelo Interventor, dois terços dos votos do departamento eram suficientes para suspender a ação até que uma decisão fosse tomada pelo chefe do Executivo federal [...]. [Assim,] não é difícil entender porque [...] o presidente do 'daspinho' era usualmente mais poderoso que o Interventor'. Como uma engrenagem, a Interventoria, o Departamento Administrativo e o Ministério da Justiça cooperavam na administração dos Estados, sob o controle geral do Presidente da República. Enquanto o Interventor agia como coordenador político, sob instruções diretas de Vargas, o Departamento Administrativo, dirigido por burocratas e integrados por engenheiros, agrônomos, estatísticos etc. - 
indivíduos que se consideravam e eram considerados imunes a pressões clientelísticas - funcionava como um corpo legislativo" (idem, p. 96-97) ${ }^{16}$.

É provável que a melhor refutação dessa interpretação do aparelho como aparelho "burocrático" tenha vindo do próprio criador dos departamentos estaduais.

Provocado a falar sobre a republicação, com algumas modificações, da Lei Orgânica dos Estados e Municípios em junho de 1939, e indagado se o regime de Vargas não estaria substituindo a gestão política dos assuntos governamentais por expedientes puramente administrativos, expulsando assim a política do território nacional, Francisco Campos, com a sinceridade habitual e com a semcerimônia com que justificava os atos mais discricionários, saiu-se com esta: "Política? Novidades políticas? Mas o que eu lhe disse já não é política? É política dotar o Brasil de leis claras e justas. É política aperfeiçoar a administração. É política realizar obras produtivas. É política aparelhar as forças armadas. É política fomentar a harmonia nacional. É política desenvolver o espírito da unidade da Pátria. Tudo isto é política, a melhor política, e essa política é a que vem praticando todos os órgãos do governo, sob a clara direção do Presidente Getúlio Vargas" (CAMPOS, 1940b, p. $171^{17}$ ).

Sem precisar estender demais a argumentação, parece o caso de retificar o ponto de vista "burocrático" expresso acima e repetido por incontáveis autores ${ }^{18}$, em três dimensões: empírica (determinação dos fatos investigados), analítica

\footnotetext{
16 A passagem entre aspas simples é do estudo de Graham sobre o DASP (cf. GRAHAM, 1968, p. 27-28). Para a mesma visão, cf. Diniz (1991, p. 110).

17 A partir de uma entrevista concedida à imprensa em 28 de julho de 1939.

18 A mesma idéia prosseguiu sem refutação. O livro de D’Araújo trata do DASP “no plano estadual” em um capítulo que tem o sugestivo título de "Administração versus política” (cf. D’ARAÚJO, 2000, em especial p. 31). Levine afirmou, em estudo mais recente, que "Para escapar à velha burocracia, Vargas criou o Departamento da Administração Pública (DASP) [sic], um superministério federal que se reportava apenas a ele, além de departamentos semelhantes em nível estadual. Essa medida permitiu ao governo inovar, criar departamentos regionais capazes de evitar lutas politicas entre grupos rivais nos estados [...]" (LEVINE, 2001, p. 85; sem grifos no original). Cf. igualmente Abreu (2007).
}

(ou seja, a análise a partir dos dados empíricos) e interpretativa (ou seja, a análise sobre o significado do objeto). É suficiente mencionar apenas a primeira dimensão e listar minhas discordâncias principais.

Para ficarmos no nível superficial da divergência: a própria expressão "daspinhos", escolhida por Graham (1968) e difundida pela literatura desde então, é equivocada tanto pelo que trata como pelo que deixa de tratar. Ela desvirtua a natureza, descaracteriza a função e falsifica a composição de cada um dos dois aparelhos estatais.

A causa mais evidente dessa incompreensão é um erro factual. Os departamentos administrativos dos estados (mais tarde, "Conselhos Administrativos dos estados") não eram divisões estaduais do DASP ${ }^{19}$. Trata-se de duas estruturas burocráticas em tudo diferentes. Uma dizia respeito ao serviço civil, outra, à gestão dos negócios políticos; uma deveria ser uma superassessoria incumbida de reorganizar a administração pública por meio de uma política orçamentária eficiente, outra pretendia funcionar como uma entidade fiscalizadora ou colaboradora das interventorias. Além de tudo, a composição de um e outro aparelho eram bastante distintas. Se o DASP reunia técnicos concursados - e era comandado, como se sabe, por um político que deveria gerar uma burocracia profissional -, os "daspinhos", por sua vez, eram integrados por outros inquilinos: os políticos profissionais (CODATO, 2008). Tomando, como exemplo, todos os conselheiros que passaram pelo Departamento Administrativo paulista entre 1939 e 1947, vê-se que não se tratava de notórios especialistas em administração pública, embora quase todos fossem bacharéis em Direito. Eram representantes dos partidos oligárquicos (extintos em dezembro de 1939) que se acomodaram mal ou não encontram um lugar no sistema de interventorias federais - e esse é um padrão que se repetia em todos os estados dos Estados Unidos do Brasil ${ }^{20}$.

\footnotetext{
19 Existiam, de fato, "daspinhos" em alguns estados, i.e., instâncias regionais do DASP; mas eles faziam parte de outra estrutura burocrática. Wahrlich observa que eles foram sendo progressivamente instituídos: no Rio de Janeiro em 1939, no Pará e na Paraíba em 1940, em Alagoas, Goiás e São Paulo em 1941, na Bahia em 1942, em Sergipe, Ceará e Espírito Santo em 1943 (WAHRLICH, 1983, p. 719).

20 Para um resumo das biografias dos conselheiros do DAESP, ver Codato (2008, p. 373-381). Para suas carrei-
} 
O mais importante, todavia, não é o formalismo dessa análise. É o que esse equívoco pressupõe e revela.

Ao identificar um aparelho com o outro, pretende-se assimilar os departamentos administrativos dos estados não aos conflitos intra-elites, mas ao projeto e ao processo de "modernização" e reforma do aparelho do Estado tentado após 1930 em que o DASP, sem dúvida, cumpriu um papel de destaque, em especial na política de recrutamento do funcionalismo -, perdendo-se o sentido político de sua inclusão no organograma do governo. Se a interpretação anterior, que chamei de "política", resumida e comentada acima, arriscava-se a importar, por contrabando, a ideologia antiliberal do regime, ao acreditar que os departamentos pudessem de fato substituir as assembléias legislativas, esta interpretação completa e radicaliza aquela, ao assumir, sem a devida reserva crítica, o discurso ideológico da racionalização da "administração pública", transferindo-o para um aparelho que poderia ser qualquer coisa, menos apolítico - seja por sua função, seja por sua composição.

Se a advertência de Francisco Campos não fosse suficiente para prevenir os analistas de que o Estado Novo, apesar do discurso oficial dos pensadores oficiais, não separava absolutamente "política" de "administração" (na verdade, submetia a segunda à primeira, dando a impressão de estar submetendo a primeira à segunda), havia sempre porta-vozes disponíveis para interpretar, explicar e propagar essa ideologia burocrática. E parece ter sido exatamente essa ideologia que foi comprada pela Sociologia brasileira.

\section{AFUNÇÃO ECONÔMICA}

$\mathrm{O}$ argumento básico da doutrina autoritária é bastante conhecido: contra o regime liberal, só o remédio da gestão racional.

Tendo então o golpe de 1937 e o sistema político erigido em nome dele disciplinado os políticos profissionais, acabado com a "caótica rivalidade partidária", aposentado o "caudilhismo regional", controlado "a extremação [sic] de conflitos

ras políticas completas (mandatos eletivos, funções políticas e burocráticas e cargos de direção partidária no Partido Republicano Paulista, Partido Democrático, Partido Comunista e Ação Integralista Brasileira), ver p. 365-368. ideológicos", detido a "infiltração comunista" e abolido o "clientelismo parlamentar"21, a questão, enfim, parece ser então a seguinte: o que faziam esses políticos de carreira abrigados no Departamento Administrativo enquanto não faziam - supostamente - a política partidária do governo?

Um exegeta comprometido com as idéias e as práticas do regime ditatorial, ao comentar o Decreto-Lei n. 1 202, aproveitou a oportunidade para censurar Júlio de Castilhos, representante do Rio Grande do Sul na Assembléia Constituinte de 1891, por pretender uma quimera: a "mais completa descentralização administrativa dentro da concentração política". Oto Prazeres, funcionário do Ministério da Justiça do Brasil, publicou um artigo em Cultura Política (órgão teórico semi-oficial do Estado Novo) para ensinar que, apesar da frase luminosa do líder gaúcho, felizmente não se pode fazer administração sem fazer política (PRAZERES, 1941). Mais que isso: a administração é a política em ação e a "verdadeira política" está em fazer que a administração seja guiada pelos "grandes e reais interesses do País". No caso, a verdadeira política resumia-se à centralização de poderes na "União Federal" (com a licença da extravagante expressão empregada pelo autor). Conforme sua explanação, a Constituição de 10 de Novembro havia estabelecido uma divisa: deveria existir, a partir de então, uma "única economia nacional e em benefício da qual" se movessem "todas as atividades nacionais". O que fez o Decreto de Abril? Fixou dois princípios, um político, outro burocrático, em perfeita harmonia entre si, para cumprir esse propósito. A nova legislação sobre a gestão dos estados e dos municípios visava estabelecer uma efetiva "cooperação" entre os poderes central e local a fim de conjugar esforços para harmonizar as rotinas da administração pública. A diversidade de métodos, a multiplicidade de critérios, a disparidade de procedimentos, especialmente na questão orçamentária ("mais de novecentas rubricas"), impedia que a Presidência da República impusesse uma orientação financeira ao país. "Criando a cooperação, tornando possível ao Poder Central presidir realmente a vida nacional, [...] o decreto-lei de abril de 1939" permitiria então ao governo "intervir e amparar a economia" (idem, p. 66, 69, 68, 69, respectivamente).

21 Todas as expressões entre aspas são das "Disposições transitórias e finais" da Carta de 1937 (cf. PORTO, 1987, p. 78-79). 
Nesse registro, "a impraticável Constituição de 1934" (da qual foi um dos redatores) não havia corrigido os defeitos da Constituição de 1891, permanecendo o que Oto Prazeres chamou de "desarmonia na administração". Essa desarmonia devia-se à ausência de "certos limites à ação dos estados e municípios". A solução desse problema, cujo foco era a política orçamentária, era mais ou menos simples: fixar tais limites na legislação. Todavia, essa racionalização de procedimentos não era um fim em si mesmo. Respondia, antes, a um propósito menos abstrato: permitir que a "União Federal" assumisse, enfim, o controle e o comando sobre a política econômica (idem, p. 63, 68, respectivamente). Os departamentos administrativos dos estados deveriam ser assim, para o autor, os executores dessa idéia.

O estudo das rotinas decisórias do Departamento Administrativo do Estado do Rio Grande do Sul torna essa formulação mais concreta. Para Camargo (1983), que classificou e analisou todos os projetos de decretos-leis e todos os processos recebidos pelo Departamento gaúcho entre 1939 e 1945, "a intervenção [do Estado nacional] nas unidades regionais refletia a pretensão de converter todos os níveis da atuação do setor público na perspectiva das funções de integração econômica e política, representadas na criação de um mercado nacional integrado, sob tutela de um Estado forte e centralizado" (idem, p. 4).

Nesse caso específico, a política do aparelho regional do estado (isto é, a ação da Interventoria em colaboração com o Departamento Administrativo) voltou-se para a proteção e a promoção dos principais produtos agropecuários do Rio Grande do Sul: arroz, carne e bebidas. As medidas de intervenção econômica eram de iniciativa da Interventoria Federal. Em seguida, eram regulamentadas "legalmente" (ou melhor: homologadas) pelo Departamento. O conteúdo das decisões estudadas atesta, segundo Camargo, o alinhamento das duas agências entre si e com os interesses da oligarquia gaúcha: a defesa dos produtos agropecuários e a tentativa de manter o perfil econômico do estado mesmo no contexto da política de industrialização por substituição de importações (conclusão que, de resto, desmente sua hipótese segundo a qual os departamentos administrativos seriam o veículo de "unificação" do mercado nacional).
Descontado o entusiasmo cívico diante da estrutura legal imposta pela "revolução brasileira" (isto é, o golpe de Estado), a hipótese de Oto Prazeres parece bem adequada, desde que combinada com os achados do estudo de Camargo, para explicar a relação entre interesses sociais, instituições políticas e política econômica nesse contexto institucional.

Como o Estado Novo pretendia regulamentar praticamente tudo - do cinema ao mate, da propaganda política à estatística, da ortografia à legislação trabalhista -, a questão do mercado interno - que era, de resto, ao lado da disputa entre "as regiões" pelo controle do aparelho do Estado, uma das questões centrais das disputas intraoligárquicas que conduziram à Revolução de 1930 - poderia encontrar, graças às múltiplas combinações políticas entre a Interventoria e o Departamento Administrativo em cada unidade dos "Estados Unidos do Brasil", uma solução para cada caso. Essa flexibilidade, resultado de uma política também muito flexível para escolher interventores federais e nomear conselheiros estaduais, foi um dos meios para conquistar e concretizar uma hierarquia diferente entre as regiões e entre as elites regionais. Todavia, a comprovação dessa hipótese depende do estudo comparado dos processos decisórios dos vários departamentos, em especial nos principais estados, já que o Rio Grande do Sul pode ser um caso anômalo.

Conforme meu entendimento, a ordem jurídica estipulada em 1937 pela Constituição e em 1939 pelo decreto-lei, se pensada em termos mais amplos, seria a via burocrática para conseguir ao menos três objetivos: $i$ ) impor a centralização das decisões, viabilizando o redirecionamento da "vocação econômica" do país (isto é, fazer que a política de industrialização, por exemplo, fosse assumida como a política principal do Estado brasileiro); ii) garantir a marginalização política de um determinado subsistema econômico regional (preterir os interesses do "complexo açucareiro" do Nordeste, por exemplo); iii) aturar algum grau de descentralização, por meio da manutenção do perfil econômico de certos subsistemas regionais, desde que esse perfil fosse funcional para o primeiro objetivo. O horizonte do governo de Vargas continuava sendo a unificação (econômica) do mercado nacional, que tinha como precondição a integração (política) dos diferentes subsistemas regionais, ação recoberta pela retórica (ideológi- 
ca) da "unidade nacional". Essa tarefa, por sua vez, dependia da, isto é, tinha como precondição a expropriação das fontes de poder das oligarquias estaduais e sua transferência para o poder Executivo federal (cf. MARTINS, 1976, p. 127). O modo de fazer isso, a partir da mesma estrutura institucional estipulada pelo Decreto-Lei n. 1202 , é que poderia variar. Eu suponho que variasse conforme os critérios de escolha de interventores e conselheiros e da relação de conflito ou colaboração daí derivada que poderia estabelecer-se entre eles. Esse procedimento estava, possivelmente, na base de um projeto político maior, embora não muito claro a todos os participantes, de reformulação da posição econômica dos subsistemas regionais.

\section{CONCLUSÕES}

A comprovação das várias proposições esparsas ao longo deste ensaio, construídas a partir das críticas à literatura disponível sobre os departamentos administrativos e, em especial, às bases que informam suas análises sobre o Estado Novo (ora percebido como um regime "tradicional", ora percebido como um regime "racional" etc.), exige um estudo mais detalhado das diversas modalidades regionais de funcionamento desse apare1ho. Essa investigação caso a caso precisa agregar o exame tanto da estrutura decisória do regime (i.e., suas instituições formais, que não são uma mera derivação do "personalismo" presidencial) quanto do processo decisório dos DAEs um dos lugares em que se fazia efetivamente a política do Estado ditatorial. Daí que seja insuficiente derivar as funções desse aparelho das atribuições que lhe facultava a legislação do regime. Além disso, precisa agregar uma variável decisiva e que ficou de fora de todas as cogitações dos analistas até aqui: o perfil da elite que pilotava essas agências.

A participação controlada das classes dirigentes estaduais na vida política estadual via Depar- tamento Administrativo permite demonstrar duas proposições mais ambiciosas sobre a relação entre elites e instituições no Brasil nesse contexto: uma que vincule a estrutura institucional do regime (sua história, seus aparelhos e seus mecanismos) ao tipo de elite (sua origem, sua trajetória, seus valores) que integra a agência inventada por Francisco Campos; outra que explique a natureza da relação daí derivada entre elites regionais e o governo central em termos menos estereotipados do que aqueles que destacam somente os "atores", seus "discursos" ou seus "conflitos pessoais", como freqüentemente acontecem nas análises focadas exclusivamente na cena política.

A utilidade da minha abordagem não consiste em revelar apenas os novos pontos de acesso dos políticos profissionais de antigamente à arena política, além da estrutura institucional mais geral que tornou esse ingresso tanto possível quanto útil "administrativamente". Mas, sim, em descrever, com base nas biografias coletivas da elite, a configuração social e política dos grupos dirigentes, ao lado da modificação do seu papel e de sua respectiva ideologia no contexto político nacional. Trata-se de explicar, enfim, as características do regime (seja seu desenho, sejam as instituições que o integram), a partir das características $d a$ elite.

A idéia central é que, mais do que resultado do grande programa de "cooptação" federal, a elite política que reina no Estado Novo é, de certa forma, produzida pelo regime e para o regime. Daí que não se trate apenas, embora também, da transposição de integrantes da elite - indivíduos - de um campo político (oligárquico) para outro (autoritário), mas da dominação, decapitação e assimilação das elites adversárias a fim de produzir uma nova classe dirigente sob medida para superar as resistências políticas, sociais e ideológicas ao processo de mudança de uma economia agroexportadora para uma economia urbano-industrial, iniciado em 1930

Adriano Codato (adriano@ufpr.br) é Doutor em Ciência Política pela Universidade Estadual de Campinas (Unicamp) e Professor de Ciência Política na Universidade Federal do Paraná (UFPR).

\section{REFERÊNCIAS BIBLIOGRÁFICAS}

ABREU, L. A. 2007. Um olhar regional sobre o Estado Novo. Porto Alegre: PUC-RS.
BELLO, J. M. 1976. História da República (18891954): síntese de sessenta e cinco anos de vida brasileira. $7^{\mathrm{a}}$ ed. São Paulo: Nacional. 
CAMARGO, D. D. 1983. Centralização e intervenção: padrão político e institucional do Estado Novo no Rio Grande do Sul - o Departamento Administrativo de Estado - RS. Porto Alegre. Dissertação (Mestrado em Ciência Política). Universidade Federal do Rio Grande do Sul.

CAMPELlO DE SOUZA, M. C. 1990 (1976). Estado e partidos políticos no Brasil (19301964). $3^{\mathrm{a}}$ ed. São Paulo: Alfa-Ômega.

CAMPOS, F. 1940a. O Estado nacional: sua estrutura; seu conteúdo ideológico. Rio de Janeiro: J. Olympio.

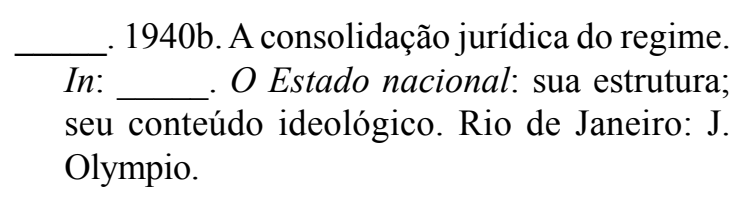

1940c. Estado nacional. In: $O E s-$ tado nacional: sua estrutura; seu conteúdo ideológico. Rio de Janeiro: J. Olympio.

1940d. Problemas do Brasil e soluções do regime. In: O Estado nacional: sua estrutura; seu conteúdo ideológico. Rio de Janeiro: J. Olympio.

1940e. Síntese da reorganização nacional. In: $O$ Estado nacional: sua estrutura; seu conteúdo ideológico. Rio de Janeiro: J. Olympio.

CARONE, E. 1977. Estado Novo (1937-1945). Rio de Janeiro: Difel.

CODATO, A. 2008. Elites e instituições no Brasil: uma análise contextual do Estado Novo. Campinas. Tese (Doutorado em Ciência Política). Universidade Estadual de Campinas.

D'ARAÚJO, M. C. 2000. O Estado Novo. Rio de Janeiro: J. Zahar.

DINIZ, E. 1991. O Estado Novo: estrutura de poder; relações de classes. In: FAUSTO, B. (org.). História geral da civilização brasileira. T. III: O Brasil Republicano; v. III: Sociedade e Política (1930-1964). $5^{a}$ ed. Rio de Janeiro: B. Brasil.

FAUSTO, B. 1972. Pequenos ensaios de história da República: 1889-1945. Cadernos CEBRAP, São Paulo, n. 10. Disponível em: http:// www.cebrap.org.br/v1/template.php?lang= pt\&area $=7$ \&pagina $=31$ \&item_biblio $=205$. Acesso em: 30.ago.2011.

\section{lo: USP.}

1995. História do Brasil. 2a ed. São Pau-

GRAHAM, L. S. 1968. Civil Service Reform in Brazil: Principles versus Practice. Austin: University of Texas.

HERTZ, A. 2004. Estado Novo: política e sociedade na ditadura de Vargas. Um estudo sobre o Departamento Administrativo do Estado do Paraná (1939-1947). Curitiba. Monografia (Graduação em Ciências Sociais). Universidade Federal do Paraná.

KAPLAN, A. 1969. A conduta na pesquisa. Metodologia para as ciências do comportamento. São Paulo: Herder.

LEVINE, R. M. 1980. O regime de Vargas, 19341938: os anos críticos. Rio de Janeiro: Nova Fronteira.

2001. Pai dos pobres? O Brasil e a era Vargas. São Paulo: Companhia das Letras.

LOEWENSTEIN, K. 1944. Brazil under Vargas. New York: Macmillan.

MARTINS, L. 1976. Pouvoir et développement économique. Formation et évolution des structures politiques au Brésil. Paris: Anthropos.

. 1983. Estado Novo. In: BELOCH, I. \& ABREU, A. A. (orgs.). Dicionário históricobiográfico brasileiro (1930-1983). V. II. Rio de Janeiro: Fundação Getúlio Vargas.

MELO FRANCO, A. A. 1979. A alma do tempo. Rio de Janeiro: J. Olympio.

MICELI, S. 1991. Carne e osso da elite política brasileira pós-1930. In: FAUSTO, B. (org.). História geral da civilização brasileira. T. III: O Brasil Republicano; v. III: Sociedade e Política (1930-1964). $5^{\text {a }}$ ed. Rio de Janeiro: B. Brasil.

NUNES, E. 1997. A gramática política do Brasil: clientelismo e insulamento burocrático. Rio de Janeiro: J. Zahar.

PAES DE BARROS, R. s/d. Discurso pronunciado por ocasião da passagem do primeiro aniversário do Departamento Administrativo do Estado de São Paulo em 11 de julho de 1940. 
In: SÃO PAULO. Departamento Administrativo do Estado. Anais de 1940. Sessões. São Paulo: s.c.p., vol. I, $2^{\mathrm{a}}$ parte.

PORTO, W. C. 1987. A Constituição de 1937. Brasília: Escopo.

PRAZERES, O. 1941. A administração de estados e municípios. Cultura Política, Rio de Janeiro, ano I, n. 7, set.

REALE, M. 1986. Memórias: destinos cruzados. São Paulo: Saraiva.

RODRIGUES, J. H. 1965. Conciliação e reforma no Brasil: um desafio histórico-cultural. Rio de Janeiro: Civilização Brasileira.
SCHWARTZMAN, S. 1975. São Paulo e o Estado nacional. São Paulo: Difel.

SOLA, L. 1990 (1968). O golpe de 37 e o Estado Novo. In: MOTA, C. G. (org.). Brasil em perspectiva. $19^{\mathrm{a}}$ ed. Rio de Janeiro: B. Brasil.

VARGAS, G. 1941. O Departamento Administrativo do Estado. In: A nova política do Brasil. V. VIII: Ferro, carvão, petróleo. Rio de Janeiro: J. Olympio.

WAHRLICH, B. M. 1983. Reforma administrativa na era de Vargas. Rio de Janeiro: Fundação Getúlio Vargas.

\section{OUTRAS FONTES}

BRASIL. 1939. Decreto-Lei n. 1 202. Dispõe sobre a administração dos Estados e dos $\mathrm{Mu}-$ nicípios. Diário Oficial da União, Rio de Janeiro, seção 1, 10.abr, p. 8113. Disponível em: http://www6.senado.gov.br/legislacao/ ListaNormas.action?numero=1202\&tipo_nor$\mathrm{ma}=\mathrm{DEL} \&$ data $=19390408 \&$ link $=\mathrm{s}$. Acesso em: 11.set.2011.
1943. Decreto-Lei n. 5 511. Altera e retifica disposições sobre a administração dos Estados e dos Municípios. Diário Oficial da União, Rio de Janeiro, seção 1, 24.maio, p. 7985. Disponível em: http://www6.senado. gov.br/legislacao/ListaNormas.action? numero $=5511 \&$ tipo_norma $=$ DEL $\&$ data $=$ 19430521\&link=s. Acesso em: 11.set.2011. 
BRAZILIAN POLITICAL SOCIOLOGY UNDER ANALYSIS: FOUR PERSPECTIVES ON THE ADMINISTRATIVE WORKINGS OF THE NEW STATE

\section{Adriano Codato}

Within Brazilian Political Sociology, there are four different views on state Administrative Departments, apparatuses created by the Vargas dictatorship in 1939 as a complement to the system of federal interventors. On the basis of these interpretations, there are also four different ways of looking at the New State regime (1937-1945) itself. Views on administrative departments diverge both according to observers' convictions regarding the way the authoritarian political system functions and according to which of these agencies' roles (political, economic, bureaucratic) the analyst considers as most salient. In this essay I analyze existing interpretations on this issue; I emphasize that which I consider to be their major difficulties and limitations in explaining the relationship between old state political elites and the new federal political institutions springing up in the Brazil of the 1940s.

KEYWORDS: New State; Getúlio Vargas; dictatorship; State Administrative Departments; Brazilian Political Sociology. 


\section{LA SOCIOLOGIE POLITIQUE BRÉSILIENNE EN ANALYSE : QUATRE VISIONS SUR LE FONCTIONNEMENT ADMINISTRATIF DU NOUVEL ETAT}

\section{Adriano Codato}

Dans les études de Sociologie politique brésilienne, il y a quatre manières différentes de considérer les Départements Administratifs des régions, des instruments créés par la dictature de Vargas en 1939 autant qu'organisme complémentaire au système d'interventions fédérales. Ces interprétations sont appuyées aussi sur quatre façons différentes de considérer le régime du Nouvel Etat (19371945) lui-même. Les conceptions sur les départements administratifs divergent par rapport aux convictions de l'observateur devant la forme de fonctionnement du système politique autoritaire et aussi par rapport au rôle (politique, économique ou bureaucratique) de ces agences soulignées selon le jugement de l'analyste. J'analyse dans cet essai les interprétations disponibles sur le sujet et je souligne ce qui me semble être les principales difficultés et limitations pour expliquer la relation entre les anciennes élites politiques régionales et les nouvelles institutions politiques fédérales dans les années 1940 au Brésil.

MOTS-CLÉS: le Nouvel Etat; Getúlio Vargas ; la dictature ; les départements administratifs des régions ; la Sociologie Politique brésilienne. 